\title{
Regulation of olfactory transduction in the Orco channel
}

\author{
Fernando Martin and Esther Alcorta* \\ Area de Genética, Departamento de Biologia Funcional, Facultad de Medicina, Universidad de Oviedo, Oviedo, Spain \\ ${ }^{*}$ Correspondence: ealcorta@uniovi.es
}

\section{A commentary on}

Phosphorylation via PKC regulates the function of the Drosophila odorant coreceptor by Sargsyan, V., Getahun, M., Llanos, S. L., Olsson, S., Hansson, B. S., and Wicher, D. (2011). Front. Cell. Neurosci. 5:5. doi: 10.3389/fncel.2011.00005

Following the discovery of olfactory receptors (ORs) in 1999 (Clyne et al., 1999; Vosshall et al., 1999), our understanding of the first steps in olfactory coding in Drosophila melanogaster has grown exponentially.

The expression of ORs follows the general rule of one OR to one olfactory sensory neuron (OSN). Characterization of ORs, OSNs, and their locations in different sensilla at OR organs (i.e., antennae and maxillary palps) has been completed (Hallem and Carlson, 2004; Vosshall and Stocker, 2007). Moreover, the map of neuronal connections made into specific glomeruli of the antennal lobe has also been reported (Fishilevich and Vosshall, 2005). This structural description of olfactory sensory elements has been followed by the functional characterization of the olfactory profiles of different ORs expressed in the so-called "empty neuron" system (Hallem and Carlson, 2006) as well as in their native OSNs (de Bruyne et al., 2001; Hallem et al., 2004).

Particular attention has been paid to the transduction process that converts the odor signal into a pattern of spikes in the OSNs. It was found that the ligandbinding ORs and their common OR83b coreceptor (now renamed Orco; Vosshall and Hansson, 2011), which form a heterodimer, exhibit an inverted topology compared to other $G$ protein coupled receptors (Benton et al., 2006; Lundin et al., 2007). In 2008, two papers published in Nature reported the use of heterologous systems transfected with Orco and one of the ORs to show that this heterodimer can act in an ionotropic manner (Sato et al., 2008; Wicher et al., 2008). However, one of these papers also reported an additional metabotropic component that was dependent on G proteins (Wicher et al., 2008). Another article using the same techniques also supported the ionotropic model (Smart et al., 2008). Reports using genetically modified flies with mutated $G$ proteins either supported (Kain et al., 2008; Chatterjee et al., 2009; Deng et al., 2011) or argued against (Yao and Carlson, 2010) the metabotropic component in the function of the OROrco heterodimer. Two hypotheses have been proposed to explain these results. It is possible that the insect ORs may be mixed ionotropic-metabotropic receptors (Wicher, 2010), or alternatively, insect ORs may be metabotropically modulated ionotropic receptors (Nakagawa and Vosshall, 2009).

In the article published in Frontiers of Cellular Neuroscience vol. 5, June 2011, the group of Wicher and Hansson present new and interesting data that further our understanding of how the OR + Orco heterodimer functions by studying the regulation of one of its components, the Orco channel (Wicher et al., 2009). In this report, the authors show that the Orco channel activity is regulated by phosphorylation via protein kinase $\mathrm{C}(\mathrm{PKC})$, which is activated by the phospholipase C (PLC) intermediate in the inositol 1,4,5-triphosphate/diacyl glycerol (IP3/DAG) transduction cascade. Wicher and Hansson employ a multidisciplinary approach, including the use of cells in culture transfected with the Orco gene to study the channel's sensitivity to cyclic adenosine monophosphate (cAMP) in the presence of different activators and inhibitors. These experiments show that $G$ proteins do not activate the Orco channel and that DAG, but not IP3, directly affects the activity of this channel. Similar results concerning the importance of DAG as second messenger have been described in the visual transduction system of insects (Hardie et al., 2002). However, a more indirect role for IP3 in olfactory transduction cannot be excluded because changes in the expression of IP3kinase 1 in OSNs have been reported to affect olfactory perception (Gomez-Diaz et al., 2006). In this case, the authors show evidence that PKC, which is activated by DAG, controls the function of the Orco channel. To confirm the action of PKC, the authors tested three mutant versions of the Orco gene that were modified in different PKC phosphorylation sites. Finally, in an attempt to understand the in vivo situation, single sensilla recordings were performed in normal flies in response to odorants after the injection of excitatory or inhibitory agents for PLC and PKC. The findings were compatible with the observations obtained from cell culture experiments.

The authors point out that they are not seeking to determine in the article whether insect ORs are mixed ionotropic and metabotropic receptors (Wicher, 2010) or metabotropically modulated ionotropic receptors (Nakagawa and Vosshall, 2009); however, these results could represent a step toward addressing this question. The use of the Orco mutant clones generated in this work, when combined with ORs in heterologous systems or expressed in flies for in vivo studies, could serve as helpful tools in future investigations. Nevertheless, even if the binding of odorant molecules to the OR-Orco dimers does not directly activate a metabotropic cascade, the results reported in this article confirm an important role for a metabotropic component in olfactory reception.

The single sensilla recordings, performed after microinjection of various pharmacological agents, demonstrated that OSNs can be metabotropically affected by modulating phosphorylation, which is in agreement with the results obtained using transfected cells. In insects, it has been reported that a single OSN can have excitatory and inhibitory responses to different odorants (Hallem and Carlson, 2006), but the mechanisms that explain this phenomenon are not known. The observed up- and downregulation of PLC/PKC may account, 
at least in part, for such differences if odor binding modulates the level of PKC in OSNs.

Finally, according to these results, the Orco channel is regulated by the interaction of elements of the IP3/DAG and cAMP transduction cascades. The existence of such a crosstalk between transduction cascades has been previously suggested in the vertebrate olfactory transduction system related to PLC, cAMP, and a kinase, in this case protein kinase $A$, although the mechanism of action and the ionic channel involved was not described (Vogl et al., 2000). The new findings regarding crosstalk between both transduction cascades and the Orco channel could also shed light on the mechanisms of regulation by metabotropic cascades in other systems and organisms.

\section{REFERENCES}

Benton, R., Sachse, S., Michnick, S. W., and Vosshall, L. B. (2006).Atypical membrane topology and heteromeric function of Drosophila odorant receptors in vivo. PLoS Biol. 4, e20. doi: 10.1371/journal.pbio.0040020

Chatterjee, A., Roman, G., and Hardin, P. E. (2009). Go contributes to olfactory reception in Drosophila melanogaster. BMC Physiol. 9, 22. doi: 10.1186/1472-6793-9-22

Clyne, P., Warr, C., Freeman, M., Lessing, D., Kim, J., and Carlson, J. (1999). A novel family of divergent seven-transmembrane proteins: candidate odorant receptors in Drosophila. Neuron 22, 327-338.

de Bruyne, M., Foster, K., and Carlson, J. R. (2001). Odor coding in the Drosophila antenna. Neuron 30,537-552.

Deng, Y., Zhang, W., Farhat, K., Oberland, S., Gisselmann, G., and Neuhaus, E. M. (2011). The stimulatory G $\alpha(\mathrm{s})$ protein is involved in olfactory signal transduction in
Drosophila.PLoS ONE6, e18605. doi: 10.1371/journal. pone.0018605

Fishilevich, E., and Vosshall, L. B. (2005). Genetic and functional subdivision of the Drosophila antennal lobe. Curr. Biol. 15, 1548-1553.

Gomez-Diaz, C., Martin, F., and Alcorta, E. (2006). The inositol 1,4,5-triphosphate kinasel gene affects olfactory reception in Drosophila melanogaster. Behav. Genet. 36, 309-321.

Hallem, E. A., and Carlson, J. R. (2004). The odor coding system of Drosophila. Trends Genet. 20, 453-459.

Hallem, E. A., and Carlson, J. R. (2006). Coding of odors by a receptor repertoire. Cell 125, 143-160.

Hallem, E. A., Ho, M. G., and Carlson, J. R. (2004). The molecular basis of odor coding in the Drosophila antenna. Cell 117, 965-979.

Hardie, R. C., Martin, F., Cochrane, G. W., Juusola, M., Georgiev, P., and Raghu, P. (2002). Molecular basis of amplification in Drosophila phototransduction: roles for $\mathrm{G}$ protein, phospholipase $\mathrm{C}$, and diacylglycerol kinase. Neuron 36, 689-701.

Kain, P., Chakraborty, T. S., Sundaram, S., Siddiqi, O., Rodrigues, V., and Hasan, G. (2008). Reduced odor responses from antennal neurons of Gqa, phospholipase $\mathrm{Cb}$, and rdgA mutants in Drosophila support a role for a phospholipid intermediate in insect olfactory transduction. J. Neurosci. 28, 4745-4755.

Lundin, C., Kall, L., Kreher, S. A., Kapp, K., Sonnhammer, E. L., Carlson, J. R., Heijne, G., and Nilsson, I. (2007). Membrane topology of the Drosophila OR83b odorant receptor. FEBS Lett. 581, 5601-5604.

Nakagawa, T., and Vosshall, L. B. (2009). Controversy and consensus: noncanonical signaling mechanisms in the insect olfactory system. Curr. Opin. Neurobiol. 19 284-292.

Sato, K., Pellegrino, M., Nakagawa, T., Nakagawa, T. Vosshall,L. B., and Touhara, K. (2008). Insect olfactory receptors are heteromeric ligand-gated ion channels. Nature 452, 1002-1006.

Smart, R., Kiely, A., Beale, M., Vargas, E., Carraher, C. Kralicek, A. V., Christie, D. L., Chen, C., Newcomb, R. D., and Warr, C. G. (2008). Drosophila odorant receptors are novel seven transmembrane domain proteins that can signal independently of heterotrimeric G proteins. Insect Biochem. Mol. Biol. 38, 770-780.

Vogl, A., Noe, J., Breer, H., and Boekhoff, I. (2000). Crosstalk between olfactory second messenger pathways. Eur. J. Biochem. 267, 4529-4535.

Vosshall, L. B., Amrein, H., Morozov, P. S., Rzhetsky, A., and Axel, R. (1999). A spatial map of olfactory receptor expression in the Drosophila antenna. Cell 96, 725-736.

Vosshall, L. B., and Hansson, B. S. (2011). A unified nomenclature system for the insect olfactory coreceptor. Chem. Senses 36, 497-498.

Vosshall, L. B., and Stocker, R. F. (2007). Molecular architecture of smell and taste in Drosophila. Annu. Rev. Neurosci. 30, 505-533.

Wicher, D. (2010). Design principles of sensory receptors. Front. Cell. Neurosci. 4:25. doi: 10.3389/ fncel.2010.00025

Wicher, D., Schäfer, R., Bauernfeind, R., Stensmyr, M. C., Heller, R., Heinemann, S. H., and Hansson, B. S. (2008).Drosophila odorant receptors are both ligandgated and cyclic-nucleotide-activated cation channels. Nature 452, 1007-1011.

Wicher, D., Schäfer, R., Bauernfeind, R., Stensmyr, M. C., Heller, R., Heinemann, S. H., and Hansson, B. S. (2009). dOr83b - receptor or ion channel?. Ann. N. Y. Acad. Sci. 1170, 164-167.

Yao, C.A., and Carlson, J. R. (2010). Role of G-proteins in odor-sensing and CO2-sensing neurons in Drosophila. J. Neurosci. 30, 4562-4572.

Received: 17 June 2011; accepted: 27 September 2011; published online: 17 October 2011.

Citation: Martin F and Alcorta E (2011) Regulation of olfactory transduction in the Orco channel. Front. Cell. Neurosci. 5:21. doi: 10.3389/fncel.2011.00021

Copyright (c) 2011 Martin and Alcorta. This is an openaccess article subject to a non-exclusive license between the authors and Frontiers Media SA, which permits use, distribution and reproduction in other forums, provided the original authors and source are credited and other Frontiers conditions are complied with. 